\title{
Study of prevalence of insulin resistance and other metabolic abnormalities in various phenotypes of polycystic ovary syndrome in central India
}

\author{
Deepti Gupta*, Rini Upadhyaya, Anjlina Bhati
}

Department of Obstetrics and Gynecology, Index Medical College Hospital and Research Center, Indore, Madhya Pradesh, India

Received: 10 May 2020

Accepted: 06 June 2020

\author{
*Correspondence: \\ Dr. Deepti Gupta, \\ E-mail: drspnagariya@gmail.com
}

Copyright: (c) the author(s), publisher and licensee Medip Academy. This is an open-access article distributed under the terms of the Creative Commons Attribution Non-Commercial License, which permits unrestricted non-commercial use, distribution, and reproduction in any medium, provided the original work is properly cited.

\section{ABSTRACT}

Background: Till recent times, defining symptoms of PCOS remained a debatable topic. In 2012, National Institute of health consensus panel proposed diagnostic criteria based on phenotypes. Evidence showed higher incidence of diabetes mellitus, insulin resistance and compensatory hyperinsulinemia among women with PCOS. So, the present study was undertaken to compare the clinical, metabolic and hormonal profile among various phenotypes in women with PCOS and to find out the prevalence of insulin resistance among the PCOS phenotypes.

Methods: The prospective, observational study was done on 292 women with PCOS-related infertility. These women were divided into 4 phenotypes. Ferriman-Gallwey score, HOMA-IR, OGTT, lipid parameters, hormonal parameters, mean ovarian volume and mean antral follicle counts were compared among the 4 phenotypic groups. One-way ANOVA followed by post-hoc Tukey was applied.

Results: Mean weight, BMI, waist circumference, SBP, DBP and Ferriman-Gallwey score, fasting glucose, fasting insulin, OGTT (1 hour) and HOMA-IR was highest in phenotype A, while fasting glucose / insulin ratio was lowest in phenotype A. Total triglycerides, total cholesterol, LDL were higher and HDL was lowest, testosterone, mean ovarian volume and mean antral follicle count were highest and vitamin D was lowest in Phenotype A.

Conclusions: Phenotype A is the group with all features of PCOS syndrome, while phenotype D is associated with milder metabolic profile. Women with phenotype A and B are at a higher risk for metabolic syndrome. Identifying various phenotypes will assist in providing appropriate treatment and prognosticating the patients with PCOS-related infertility.

Keywords: Infertility, Metabolic syndrome, Phenotypes, Polycystic ovary syndrome-related infertility, Rotterdam criteria

\section{INTRODUCTION}

Polycystic ovary syndrome (PCOS) is a heterogeneous condition characterized by a complex range of reproductive and metabolic disorders and has a prevalence of about 2.5 to 11.9 percent. ${ }^{1}$ Defining symptoms of PCOS have developed since 1935 and remain a topic of debate among physicians and scientists worldwide to date. ${ }^{2-4}$ This is a complex condition that affects not only the reproductive system but also obesity, insulin resistance, type 2 diabetes mellitus, dyslipidemia, and metabolic syndrome..$^{5-7}$

Classification of PCOS has been attempted many a times. Initially in 1990, National Institute of Health developed its criteria, which listed women with hyperandrogenism and oligo-anovulation as having polycystic ovarian syndrome, when all the other endocrine disorders were also excluded. ${ }^{8}$ 
The Rotterdam Expert Committee gave the second description which included the existence of two of the three characteristics: clinical or biochemical hyperandrogenism, oligo-anovulation, and ultrasound polycystic ovaries. ${ }^{9}$ The Androgen Excess and PCOS Society (AE-PCOS) criteria came in 2006, considering the background that hyperandrogenism is the strongest determinant which affects the pathophysiology of PCOS. ${ }^{10}$ This criteria believed that the diagnosis of PCOS should be based on clinical or biochemical hyperandrogenism in tandem with oligo-anovulation or polycystic ovaries. But this criterion had to exclude the women with non-hyperandrogenic phenotypic PCOS, so it again created dilemma in the diagnosis of PCOS. Considering these lacunae and dilemma, finally in 2012, National Institute of health consensus panel proposed a newer diagnostic criterion based on phenotypes. ${ }^{11}$ Phenotype A (full-blown syndrome PCOS) includes hyperandrogenism (HA) (clinical or biochemical), ovulatory dysfunction (OD), and polycystic ovaries (PCO) (HA+OD+PCO). Phenotype B (non-PCO PCOS: $\mathrm{HA}+\mathrm{OD}$ ) includes hyperandrogenism (HA) and ovulatory dysfunction (OD). Phenotype $\mathrm{C}$ (ovulatory PCOS: $\mathrm{HA}+\mathrm{PCO}$ ) includes hyperandrogenism (HA) and polycystic ovaries (PCO). Phenotype D (nonhyperandrogenic PCOS: OD+PCO) includes ovulatory dysfunction (OD) and polycystic ovaries (PCO).

Whether the four phenotypes reflect a broad range of the same disorder, PCOS, is still uncertain. There are minimal clinical character and endocrine metabolic data currently available for women belonging to the novel PCOS phenotypes identified by Rotterdam criteria and it is important to document variations in the subjects within the four PCOS classes to determine whether or not they are distinct, overlapping or not. ${ }^{12}$

There is strong evidence that shows a high propensity of developing diabetes mellitus type-2 in women with PCOS and insulin resistance and compensatory hyperinsulinemia have been found to be the key elements of PCOS. ${ }^{13-17}$ Stimulation of ovarian androgen production has been found directly or indirectly linked to insulin and has been found to produce reproductive disturbances.

At present, hyper-insulinemic euglycemic clamp is the gold standard for the diagnosis of insulin resistance, but has been found to be not feasible when screening large population or for routine time-based evaluation of individuals at risk. ${ }^{18}$ But there are some other methods by which insulin resistance can be diagnosed. They include fasting insulin (FI), fasting blood sugar (FBS)/FI, homeostatic model assessment of insulin resistance (HOMA-IR) and quantitative insulin sensitivity check index (QUICKI). ${ }^{19-22}$

The present study was undertaken to find and compare the clinical, metabolic and hormonal profile among the various phenotypes and also to find out the prevalence of insulin resistance in relation to PCOS phenotypes in the rural part of Central India.

\section{METHODS}

The present prospective, observational study was conducted in the department of obstetrics and gynecology, Index Medical College Hospital and Research Centre, Indore, Madhya Pradesh from January $1^{\text {st }}, 2018$ to June $30^{\text {th }}, 2019$. All women who were having PCOS (based on Rotterdam's criteria, related infertility of age less than 40 years, presented in outdoor department were enrolled for study initially and data collection was done. ${ }^{9}$ Thus, a total of 390 women were contacted in the study. But 73 women were excluded after primary evaluation. Exclusion criteria included women with other hormonal diseases like high $\mathrm{TSH}$, hyperprolactinemia and other coexistent causes of infertility so women on any insulin-sensitizing agent or lipid-lowering agent or having an endocrine disorder or anorexia nervosa / bulimia nervosa or with hypothalamic or pituitary dysfunction were excluded from the study.

Twenty-five women were lost to follow-up during the course of the study so were also excluded. Finally, the analysis was carried on 292 women with PCOS-related infertility, who were classified into four PCOS phenotypes based on the NIH consensus panel criteria. ${ }^{11}$

A voluntary written informed consent was obtained from either woman and/or her legally acceptable representative for participation in the study before enrolling in women into the study. Clearance from the Institutional Ethics Committee was obtained prior to initiation of the study in the institution.

\section{Methodology}

The physical examination of the enrolled women included their age, blood pressure, weight $(\mathrm{kg})$ and height (cm). Body mass index (BMI) was recorded with the above measurements. Waist circumference (WC) was measured midway between lower rib margin and the iliac crest in the mid-axillary line at the end of normal expiration. ${ }^{32}$ Hip circumference was measured with the measuring tape at the highest prominence of the buttocks and parallel to the floor. ${ }^{23}$ Waist and hip circumference were recorded after removing clothing from the area over waist and hip. Thyroid and breast were examined for any abnormalities. Signs of androgen excess were looked for like excessive hair growth, acne, or alopecia. Excessive hair growth was graded by the modified Ferriman and Gallwey (FG) score. ${ }^{24}$

FIGO classification was used to characterize menstrual irregularity. ${ }^{25}$ The cycle length of 24-38 days was considered as normal and length $>38$ days were included in the oligomenorrheic group. 
All the women enrolled in the study were called on the day 2-3 of their next menstrual cycle for baseline investigations like Follicle stimulating hormone (FSH), luteinizing hormone (LH), anti-mullerian hormone (AMH), 17-hydroxyprogesterone levels (17-OHP), testosterone, androstenedione, vitamin-D, fasting triglycerides, high density lipoprotein (HDL), low density lipoprotein (LDL), and cholesterol levels.

$\mathrm{LH}, \mathrm{FSH}, \mathrm{AMH}$, testosterone, vitamin $\mathrm{D}$, and insulin were determined in the fasting plasma samples of the study subjects by electrochemiluminescence immunoassay (ECLIA).

Baseline transvaginal scan (TVS) was also done on the same visit (day 2) for ovarian volume and antral follicle count (AFC) using a Philips ultrasound machine, model IU22 (probe frequency range 5-7 MHz).

\section{Indirect methods for insulin resistance diagnosis}

Indirect methods for diagnosis of insulin resistance used in this study were:

- Fasting insulin: A fasting insulin of more than or equal to $30 \mu \mathrm{U} / \mathrm{ml}$ in woman with PCOS was considered as having insulin resistance.

- Fasting plasma glucose: Fasting plasma glucose test is done after 8 hours of fasting. A plasma glucose level between 100 and $125 \mathrm{mg} / \mathrm{dL}$ was taken as impaired fasting glucose or prediabetes. A value of more than $126 \mathrm{mg} / \mathrm{dL}$ is considered as diabetes.

- Glucose $(G)$ /insulin ratio (I): A G/I ratio of less than 4.5 has been found to be good indicator of insulin resistance with a sensitivity of $95 \%$ and specificity of $84 \%$.

- Homeostatic model assessment (HOMA-IR): The product of the fasting values of glucose (expressed as $\mathrm{mg} / \mathrm{dL}$ ) and insulin (expressed as $\mu \mathrm{U} / \mathrm{mL}$ ) is divided by a constant: $\mathrm{I} 0 \times \mathrm{G} 0 \div 405$ to calculate HOMA-IR. The HOMA calculation compensates for fasting hyperglycemia. A value of more than $2(>2)$ is defined as having insulin resistance. ${ }^{17}$

- Oral glucose tolerance test: It is a better option than fasting techniques as many women may have normal fasting glucose levels despite abnormal 2-hour fasting level. The OGTT uses a 75-g glucose load and measures glucose and insulin at various intervals over 1 to 3 hours.

\section{Outcome measures}

Fasting insulin, fasting plasma glucose, blood glucose levels at 1 hour and 2 hour after taking $75 \mathrm{gm}$ oral glucose, Follicle stimulating hormone (FSH), luteinizing hormone (LH), anti-mullerian hormone (AMH), 17hydroxyprogesterone levels (17-OHP), testosterone, androstenedione, vitamin-D, fasting triglycerides, high density lipoprotein (HDL), low density lipoprotein (LDL), cholesterol levels, ovarian volume and antral follicle count formed the outcome measures of the study.

\section{Statistical analysis}

The data was collected in the customized proforma designed specifically for the study purpose. All the descriptive data was presented in the form of numbers and percentages. Comparison of means of various parameters among the phenotypes was done using Oneway ANOVA followed by Post-hoc Tukey test. A p value of $<0.05$ was taken as statistically significant.

\section{RESULTS}

All the data were obtained, analysed and compiled in tabulated form.

Table 1: Distribution of various PCOS phenotypes.

\begin{tabular}{|llll|}
\hline PCOS phenotype & Definition & Includes & Distribution \\
\hline A & Full blown PCOS & HA+OD+PCO & $198(67.8 \%)$ \\
\hline B & Non PCO PCOS & HA+OD & $32(10.95 \%)$ \\
\hline C & Ovulatory PCOS & HA+PCO & $52(17.8 \%)$ \\
\hline D & Non-hyperandrogenic PCOS & OD+PCO & $10(3.42 \%)$ \\
\hline
\end{tabular}

The most common PCOS phenotype in this study was the full-blown PCOS (phenotype A) which includes all three features: hyperandrogenism, irregular cycles and PCOs on ultrasound. It's prevalence was $67.8 \%$. While the prevalence of phenotypes B, C and D were $10.95 \%$, $17.8 \%$ and $3.42 \%$ respectively.

Comparison of age, weight, BMI, waist circumference, SBP, DBP and Ferriman-Gallwey score were found to be statistically different among the phenotypes A, B, C and $\mathrm{D}(\mathrm{p}<0.05)$.
Age: Highest age was seen in phenotype A and lowest in phenotype B. Age in Phenotype A was significantly higher than phenotypes $B$ and $C(p<0.05)$.

Weight: Maximum weight was seen in phenotype A and lowest weight in phenotype D. Weight in phenotype A was significantly higher than phenotypes B, C and D $(\mathrm{p}<0.05)$.

BMI: Highest BMI was seen in phenotype A and lowest in phenotype $\mathrm{C}$. BMI in phenotype $\mathrm{A}$ was significantly 
higher than phenotypes $\mathrm{B}, \mathrm{C}$ and $\mathrm{D}(\mathrm{p}<0.05)$ and $\mathrm{BMI}$ in phenotype $\mathrm{B}$ was significantly higher than phenotype $\mathrm{C}$ $(\mathrm{p}<0.05)$.

Waist circumference: Largest waist circumference was seen in phenotype A and lowest in phenotype C. Waist circumference was significantly higher in phenotype $\mathrm{A}$ in comparison to phenotype $\mathrm{C}(\mathrm{p}<0.05)$.

Systolic blood pressure: Highest SBP was seen in phenotype A and lowest in phenotype B. SBP in phenotype A was significantly higher than phenotypes B, $C$ and $D \quad(p<0.05)$ and SBP in phenotype $B$ was significantly higher than phenotype $\mathrm{C}(\mathrm{p}<0.05)$.

Diastolic blood pressure: Highest DBP was seen in phenotype $\mathrm{A}$ and lowest in phenotype $\mathrm{B}$. DBP in phenotype A was significantly higher than phenotypes B, $\mathrm{C}$ and $\mathrm{D}(\mathrm{p}<0.05)$.

Ferriman-Gallwey score: Ferriman-Gallwey score was highest in phenotype and lowest in phenotype D. Ferriman-Gallwey score was significantly higher in phenotype $\mathrm{A}$ in comparison to phenotypes $\mathrm{C}$ and $\mathrm{D}$ $(p<0.05)$. It was significantly higher in phenotype $B$ in comparison to phenotypes $\mathrm{C}$ and $\mathrm{D}(\mathrm{p}<0.05)$ and in phenotype $\mathrm{C}$ was significantly higher than in phenotype $\mathrm{D}(\mathrm{p}<0.05)$.

Fasting glucose: It was highest in phenotype A and lowest in phenotype D. Fasting glucose was significantly higher in phenotype A in comparison to phenotypes B, C and $\mathrm{D}(\mathrm{p}<0.05)$.

Table 2: Comparison of demographic variables, vitals and Ferriman-Gallwey Score among the various phenotypes.

\begin{tabular}{|c|c|c|c|c|c|c|c|c|c|c|c|c|}
\hline \multirow{2}{*}{$\begin{array}{l}\text { Clinical } \\
\text { profile }\end{array}$} & \multirow{2}{*}{$\begin{array}{l}\text { Pheno-type } \\
\text { A }(\text { mean } \pm \text { SD }) \\
(\mathrm{n}=198)\end{array}$} & \multirow{2}{*}{$\begin{array}{l}\text { Pheno-type } \\
\text { B (mean } \pm \text { SD } \\
(\mathrm{n}=32)\end{array}$} & \multirow{2}{*}{$\begin{array}{l}\text { Pheno-type } \\
\text { C (mean } \pm \text { SD } \\
(n=52)\end{array}$} & \multirow{2}{*}{$\begin{array}{l}\text { Pheno-type } \\
\text { D (mean } \pm \text { SD } \\
(\mathrm{n}=10)\end{array}$} & \multirow{2}{*}{ F valuu } & \multirow[b]{2}{*}{ p value } & \multicolumn{6}{|c|}{ Post Hoc } \\
\hline & & & & & & & A-B & A-C & A-D & B-C & B-D & C-D \\
\hline Age & $30.34 \pm 3.57$ & $27.45 \pm 2.97$ & $28.57 \pm 3.01$ & $29.98 \pm 2.75$ & 8.98 & $0.001 *$ & $\mathrm{~S}$ & $\mathrm{~S}$ & NS & NS & NS & NS \\
\hline Weight (kg) & $68.08 \pm 10.05$ & $59.67 \pm 9.97$ & $55.42 \pm 10.67$ & $54.09 \pm 6.7$ & 28.46 & $0.001 *$ & $S$ & $S$ & $\mathrm{~S}$ & NS & NS & NS \\
\hline BMI $\left(\mathrm{kg} / \mathrm{m}^{2}\right)$ & $28.99 \pm 3.42$ & $25.78 \pm 3.51$ & $23.76 \pm 3.41$ & $24.98 \pm 3.69$ & 37.36 & $0.001 *$ & S & S & S & S & NS & NS \\
\hline $\begin{array}{l}\text { Waist } \\
\text { circumference } \\
\text { (inches) }\end{array}$ & $36.04 \pm 3.30$ & $35.06 \pm 2.05$ & $33.05 \pm 4.5$ & $34.06 \pm 7.8$ & 9.67 & $0.001 *$ & NS & S & NS & NS & NS & NS \\
\hline SBP mmHg & $128.04 \pm 7.8$ & $115.03 \pm 5.6$ & $120.07 \pm 6.7$ & $118.56 \pm 7.6$ & 40.69 & $0.001 *$ & $\mathrm{~S}$ & S & $S$ & $\mathrm{~S}$ & NS & NS \\
\hline DBP mmHg & $80.23 \pm 7.3$ & $72.58 \pm 4.5$ & $75.05 \pm 4.7$ & $74.05 \pm 5.6$ & 19.25 & $0.001^{*}$ & S & $\mathrm{S}$ & $\mathrm{S}$ & NS & NS & NS \\
\hline $\begin{array}{l}\text { Ferriman- } \\
\text { Gallwey score }\end{array}$ & $14.45 \pm 2.30$ & $13.56 \pm 1.12$ & $10.89 \pm 1.17$ & $5.95 \pm 0.25$ & 91.84 & $0.001 *$ & NS & S & $S$ & $S$ & $S$ & S \\
\hline
\end{tabular}

One-way ANOVA followed by post-hoc tukey applied. p value $<0.05$ was taken as statistically significant.

Table 3: Comparison of metabolic parameters among the various phenotypes.

\begin{tabular}{|c|c|c|c|c|c|c|c|c|c|c|c|c|}
\hline \multirow{2}{*}{$\begin{array}{l}\text { Metabolic } \\
\text { profile }\end{array}$} & \multirow{2}{*}{$\begin{array}{l}\text { Pheno-type } \\
\text { A (mean } \pm \text { SD } \\
(\mathrm{n}=198)\end{array}$} & \multirow{2}{*}{$\begin{array}{l}\text { Pheno-type } \\
\text { B (mean } \pm \text { SD } \\
(n=32)\end{array}$} & \multirow{2}{*}{$\begin{array}{l}\text { Pheno-type } \\
C(\text { mean } \pm S D \\
(n=52)\end{array}$} & \multirow{2}{*}{$\begin{array}{l}\text { Pheno-type } \\
\text { D (mean } \pm \text { SD } \\
(n=10)\end{array}$} & \multirow{2}{*}{ F valve } & \multirow[b]{2}{*}{ p value } & \multicolumn{6}{|c|}{ Post-Hoc } \\
\hline & & & & & & & A-B & A-C & A-D & B-C & B-D & C-D \\
\hline $\begin{array}{l}\text { Fasting glucose } \\
(\mathrm{mg} / \mathrm{dL})\end{array}$ & $95.54 \pm 10.5$ & $90.15 \pm 6.7$ & $89.67 \pm 1.5$ & $85.35 \pm 4.5$ & 10.701 & $0.001 *$ & $\mathrm{~S}$ & $S$ & S & NS & NS & NS \\
\hline $\begin{array}{l}\text { Fasting insulin } \\
(\mu \mathrm{IU} / \mathrm{L})\end{array}$ & $23.28 \pm 5.25$ & $18.45 \pm 4.86$ & $19.25 \pm 4.67$ & $15.25 \pm 3.39$ & 20.292 & $0.001 *$ & S & S & $\mathrm{S}$ & NS & NS & NS \\
\hline $\begin{array}{l}\text { Fasting glucose } \\
\text { insulin ratio }\end{array}$ & $4.10 \pm 1.15$ & $4.88 \pm 1.02$ & $4.65 \pm 1.07$ & $5.59 \pm 1.06$ & 10.987 & $0.001 *$ & S & S & $S$ & NS & NS & NS \\
\hline $\begin{array}{l}\text { OGTT (1 hour) } \\
\text { (mg/dL) }\end{array}$ & $155.04 \pm 25.45$ & $147.05 \pm 30.25$ & $145.04 \pm 27.8$ & $\begin{array}{l}140.05 \pm 35 . \\
5\end{array}$ & 3.044 & $0.029 *$ & NS & NS & NS & NS & NS & NS \\
\hline $\begin{array}{l}\text { OGTT ( } 2 \text { hour) } \\
(\mathrm{mg} / \mathrm{dL})\end{array}$ & $135.5 \pm 30.5$ & $129.6 \pm 33.7$ & $125.8 \pm 32.04$ & $120.9 \pm 40.7$ & 1.924 & $\begin{array}{l}0.125, \\
\text { NS }\end{array}$ & NS & NS & NS & NS & NS & NS \\
\hline HOMA-IR & $5.49 \pm 1.25$ & $4.10 \pm 1.85$ & $4.26 \pm 1.24$ & $3.21 \pm 1.05$ & 25.516 & $0.001 *$ & S & $\mathrm{S}$ & S & NS & NS & NS \\
\hline
\end{tabular}

One-way ANOVA followed by post-hoc turkey applied. p value $<0.05$ was taken as statistically significant.

Fasting insulin: It was highest in phenotype A and lowest in phenotype D. Fasting insulin was significantly higher in phenotype $\mathrm{A}$ in comparison to phenotypes $\mathrm{B}, \mathrm{C}$ and $\mathrm{D}$ $(\mathrm{p}<0.05)$.
Fasting glucose/insulin: It was highest in phenotype D and lowest in phenotype A. Fasting glucose/insulin was significantly lower in phenotype $\mathrm{A}$ in comparison to phenotypes B, C and D ( $<<0.05)$. 
Table 4: Comparison of lipid parameters among various phenotypes.

\begin{tabular}{|c|c|c|c|c|c|c|c|c|c|c|c|c|}
\hline \multirow{2}{*}{$\begin{array}{l}\text { Lipid } \\
\text { profile }\end{array}$} & \multirow{2}{*}{$\begin{array}{l}\text { Pheno-type } \\
\text { A }(\text { mean } \pm \text { SD }) \\
(n=198)\end{array}$} & \multirow{2}{*}{$\begin{array}{l}\text { Pheno-type } \\
\text { B }(\text { mean } \pm \text { SD }) \\
(n=32)\end{array}$} & \multirow{2}{*}{$\begin{array}{l}\text { Pheno-type } \\
\text { C (mean } \pm \text { SD }) \\
(n=52)\end{array}$} & \multirow{2}{*}{$\begin{array}{l}\text { Pheno-type } \\
\text { D (mean } \pm \text { SD }) \\
(n=10)\end{array}$} & \multirow{2}{*}{$\begin{array}{l}\mathbf{F} \\
\text { value }\end{array}$} & \multirow[b]{2}{*}{$\begin{array}{l}\mathbf{p} \\
\text { value }\end{array}$} & \multicolumn{3}{|c|}{ Post Hoc } & \multirow[b]{2}{*}{ B-C } & \multirow[b]{2}{*}{ B-D } & \multirow[b]{2}{*}{ C-D } \\
\hline & & & & & & & A-B & A-C & A-D & & & \\
\hline $\begin{array}{l}\text { Total } \\
\text { triglycerides } \\
(\mathrm{mg} / \mathrm{dl})\end{array}$ & $140.65 \pm 40.2$ & $125.5 \pm 38.9$ & $119.56 \pm 45.5$ & $155.5 \pm 52.8$ & 4.964 & $0.002 *$ & NS & $\mathrm{S}$ & NS & NS & NS & NS \\
\hline $\begin{array}{l}\text { Total } \\
\text { cholesterol } \\
(\mathrm{mg} / \mathrm{dl})\end{array}$ & $180.67 \pm 42.8$ & $150.5 \pm 42.8$ & $155.9 \pm 32.6$ & $160.6 \pm 40.67$ & 8.763 & $0.001 *$ & S & $S$ & NS & NS & NS & NS \\
\hline LDL (mg/dl) & $116.56 \pm 23.6$ & $110.6 \pm 20.7$ & $105.6 \pm 29.7$ & $103.9 \pm 30.6$ & 3.422 & $0.017 *$ & NS & S & NS & NS & NS & NS \\
\hline HDL (mg/dl) & $45.5 \pm 10.5$ & $51.7 \pm 9.8$ & $52.6 \pm 11.5$ & $55.05 \pm 8.8$ & 9.730 & $0.001 *$ & NS & $S$ & S & NS & NS & NS \\
\hline
\end{tabular}

One-way ANOVA followed by post-hoc tukey applied. $\mathrm{p}$ value $<0.05$ was taken as statistically significant.

Table 5: Comparison of mean hormonal parameters among various phenotypes.

\begin{tabular}{|c|c|c|c|c|c|c|c|c|c|c|c|c|}
\hline \multirow{2}{*}{$\begin{array}{l}\text { Hormonal } \\
\text { profile }\end{array}$} & \multirow{2}{*}{$\begin{array}{l}\text { Pheno-type } \\
\text { A (mean } \pm \text { SD }) \\
(\mathrm{n}=198)\end{array}$} & \multirow{2}{*}{$\begin{array}{l}\text { Pheno-type } \\
\text { B }(\text { mean } \pm \text { SD }) \\
(n=32)\end{array}$} & \multirow{2}{*}{$\begin{array}{l}\text { Pheno-type } \\
\text { C (mean } \pm \text { SD }) \\
(\mathrm{n}=52)\end{array}$} & \multirow{2}{*}{$\begin{array}{l}\text { Pheno-type } \\
\text { D (mean } \pm \text { SD) } \\
(\mathrm{n}=10)\end{array}$} & \multirow{2}{*}{$\begin{array}{l}\text { F } \\
\text { value }\end{array}$} & \multirow[b]{2}{*}{$\begin{array}{l}\mathbf{p} \\
\text { value }\end{array}$} & \multicolumn{3}{|c|}{ Post Hoc } & \multirow[b]{2}{*}{ B-C } & \multirow[b]{2}{*}{ B-D } & \multirow[b]{2}{*}{ C-D } \\
\hline & & & & & & & A-B & A-C & A-D & & & \\
\hline LH (IU/I) & $13.64 \pm 7.54$ & $15.98 \pm 5.5$ & $13.89 \pm 9.97$ & $10.45 \pm 5.34$ & 1.481 & $\begin{array}{l}0.219, \\
\text { NS }\end{array}$ & NS & NS & NS & NS & NS & NS \\
\hline FSH (IU/I) & $5.78 \pm 2.45$ & $6.46 \pm 3.56$ & $5.05 \pm 2.98$ & $4.76 \pm 1.67$ & & $0.071^{*}$ & NS & NS & NS & NS & NS & NS \\
\hline LH:FSH & $2.35 \pm 1.87$ & $2.47 \pm 1.35$ & $2.75 \pm 1.45$ & $2.19 \pm 1.67$ & 0.789 & $\begin{array}{l}0.500, \\
\text { NS }\end{array}$ & NS & NS & NS & NS & NS & NS \\
\hline 17OHP (ng/dl) & $1.54 \pm 0.65$ & $1.43 \pm 0.25$ & $1.58 \pm 0.35$ & $100+018$ & 2377 & $0.018^{*}$ & NS & NS & $S$ & NS & NS & $S$ \\
\hline Vit D & $20.45 \pm 5.35$ & $22.09 \pm 8.8$ & $28.06 \pm 8.75$ & $30.06 \pm 2.5$ & 24.050 & $0.001 *$ & NS & S & $S$ & $\mathrm{~S}$ & $\mathrm{~S}$ & NS \\
\hline $\begin{array}{l}\text { Testosterone } \\
(\mathrm{nmol} / \mathrm{l})\end{array}$ & $3.18 \pm 1.47$ & $2.82 \pm 0.89$ & $2.72 \pm 1.04$ & $1.72 \pm 0.65$ & 5.258 & $0.001 *$ & NS & NS & S & NS & NS & NS \\
\hline AMH (ng/ml) & $12.4 \pm 56.35$ & $9.79 \pm 4.32$ & $11.04 \pm 4.67$ & $7.74 \pm 2.35$ & 0.060 & $\begin{array}{l}0.980, \\
\text { NS }\end{array}$ & NS & NS & NS & NS & NS & NS \\
\hline
\end{tabular}

One-way ANOVA followed by post-hoc turkey applied. $\mathrm{p}$ value $<0.05$ was taken as statistically significant.

Table 6: Comparison of ultrasound findings among various phenotypes.

\begin{tabular}{|c|c|c|c|c|c|c|c|c|c|c|c|c|}
\hline \multirow{2}{*}{$\begin{array}{l}\text { Ultrasound } \\
\text { findings }\end{array}$} & \multirow{2}{*}{$\begin{array}{l}\text { Pheno-type } \\
\text { A }(\text { mean } \pm \text { SD }) \\
(n=198)\end{array}$} & \multirow{2}{*}{$\begin{array}{l}\text { Pheno-type } \\
\text { B (mean } \pm \text { SD }) \\
(\mathrm{n}=32)\end{array}$} & \multirow{2}{*}{$\begin{array}{l}\text { Pheno-type } \\
\text { C (mean } \pm \text { SD }) \\
(\mathrm{n}=52)\end{array}$} & \multirow{2}{*}{$\begin{array}{l}\text { Pheno-type } \\
\text { D (mean } \pm \text { SD }) \\
(n=10)\end{array}$} & \multirow{2}{*}{$\begin{array}{l}\text { F } \\
\text { value }\end{array}$} & \multirow{2}{*}{$\begin{array}{l}\text { p } \\
\text { value }\end{array}$} & \multicolumn{3}{|c|}{ Post Hoc } & \multirow[b]{2}{*}{ B-C } & \multirow[b]{2}{*}{ B-D } & \multirow[b]{2}{*}{ C-D } \\
\hline & & & & & & & A-B & A-C & A-D & & & \\
\hline $\begin{array}{l}\text { Mean ovarian } \\
\text { volume }(\mathrm{cm})\end{array}$ & $14.68 \pm 3.69$ & $9.57 \pm 1.86$ & $12.08 \pm 3.77$ & $13.45 \pm 0.98$ & 23.732 & $0.001 *$ & S & S & NS & $S$ & $S$ & NS \\
\hline $\begin{array}{l}\text { Mean antral } \\
\text { follicle count }\end{array}$ & $13.78 \pm 3.67$ & $9.89 \pm 1.98$ & $11.02 \pm 3.56$ & $7.98 \pm 3.36$ & 23.238 & $0.001 *$ & $S$ & S & $S$ & NS & NS & NS \\
\hline
\end{tabular}

One-way ANOVA followed by post-hoc turkey applied. p value $<0.05$ was taken as statistically significant.

OGTT (1 hour): It was highest in phenotype A and lowest in phenotype D. OGTT (1 hour) was comparable among all the phenotypes $(\mathrm{p}>0.05)$.

OGTT (2 hours): It was highest in phenotype A and lowest in phenotype D. OGTT (2 hour) was comparable among all the phenotypes $(\mathrm{p}>0.05)$.

HOMA-IR: It was highest in phenotype A and lowest in phenotype D. HOMA-IR was significantly higher in phenotype $\mathrm{A}$ in comparison to phenotypes $\mathrm{B}, \mathrm{C}$ and $\mathrm{D}$ $(\mathrm{p}<0.05)$.

Total triglycerides: It was highest in phenotype D and lowest in phenotype B. Total triglycerides was significantly higher in phenotype $\mathrm{A}$ in comparison to phenotype $\mathrm{C}(\mathrm{p}<0.05)$.

Total cholesterol: It was highest in phenotype A and lowest in phenotype B. Total cholesterol was significantly higher in Phenotype $\mathrm{A}$ in comparison to phenotypes B and C $(\mathrm{p}<0.05)$.

$L D L$ : It was highest in phenotype $\mathrm{A}$ and lowest in phenotype D. LDL was significantly higher in phenotype A in comparison to phenotype $C(p<0.05)$.

$H D L$ : It was highest in phenotype $\mathrm{D}$ and lowest in phenotype A. HDL was significantly lower in phenotype $A$ in comparison to phenotypes B and $C(p<0.05)$. 
LH: It was highest in phenotype $\mathrm{B}$ and lowest in phenotype D. LH was comparable among all the various phenotypes $(\mathrm{p}>0.05)$.

FSH: It was highest in phenotype $\mathrm{B}$ and lowest in phenotype D. FSH was comparable among all the various phenotypes $(\mathrm{p}>0.05)$.

LH:FSH ratio: It was highest in phenotype $\mathrm{C}$ and lowest in phenotype D. LH:FSH ratio was comparable among all the various phenotypes $(\mathrm{p}>0.05)$.

17OHP: It was highest in phenotype $\mathrm{C}$ and lowest in phenotype D. 17OHP was significantly lower in phenotype $\mathrm{D}$ in comparison to phenotypes $\mathrm{A}$ and $\mathrm{C}$ $(\mathrm{p}<0.05)$.

Vitamin D: It was highest in phenotype D and lowest in phenotype A. Vitamin D was significantly lower in phenotype $\mathrm{A}$ in comparison to phenotypes $\mathrm{C}$ and $\mathrm{D}$ $(p<0.05)$ and also it was significantly lower in phenotype $\mathrm{B}$ in comparison to phenotypes $\mathrm{C}$ and $\mathrm{D}(\mathrm{p}<0.05)$.

Testosterone: It was highest in phenotype A and lowest in phenotype D. Testosterone was significantly higher in phenotype $\mathrm{A}$ in comparison to phenotype $\mathrm{D}(\mathrm{p}<0.05)$.

$A M H$ : It was highest in phenotype $\mathrm{A}$ and lowest in phenotype D. AMH was comparable among all the various phenotypes $(\mathrm{p}>0.05)$.

Mean ovarian volume: It was highest in phenotype A and lowest in phenotype B. Mean ovarian volume in phenotype A was significantly higher in comparison to phenotypes $B$ and $C(p<0.05)$. The mean ovarian volume in phenotype B was significantly lower in comparison to phenotypes $C$ and $D(p<0.05)$.

Mean antral follicle count: It was highest in phenotype A and lowest in phenotype D. The mean antral follicle count was significantly higher in Phenotype $\mathrm{A}$ in comparison to phenotypes $\mathrm{B}, \mathrm{C}$ and $\mathrm{D}(\mathrm{p}<0.05)$.

\section{DISCUSSION}

PCOS appearance is not homogeneous, as it relies on the presence or absence of three elements: hyperandrogenism, menstrual irregularity and the phenotypic type PCO. There are different phenotypes regarding their physiological, metabolic, hormonal profile which also alters their response to ovulationinducing agents such as clomiphene. These differences mean that each PCOS phenotype is a variation of a common syndrome. In the literature various hypotheses were provided to explain this heterogeneity in clinical presentation. It may be an interplay between genetic and environmental factors affecting PCOS pathogenesis. ${ }^{26}$ Another potential reason provided is intrauterine exposure to maternal androgens that could be responsible for a particular phenotype. ${ }^{7}$ Studies are available to show that excessive androgen exposure to the fetus influences the hypothalamic-pituitary-ovarian axis resulting in adverse reproductive and metabolic effects. ${ }^{26}$

According to some figures, the Rotterdam criterion may have raised the incidence of this disease in the female reproductive age population by as much as $50 \%$. Identifying common clinical characteristics in women with PCOS has diagnostic implications in looking for particular genetic determinants and designing apposite treatment schemes for different manifestations of disease. $^{27}$

There were $67.8 \%$ women in phenotype A, $10.95 \%$ women in phenotype $\mathrm{B}, 17.8 \%$ women in phenotype $\mathrm{C}$ and $3.42 \%$ women in phenotype D. According to the study done by Gulszak et al, there were $60.2 \%, 16.1 \%$, $18.3 \%$ and $5.4 \%$ women in phenotype A, B, C and D respectively, which is similar to this finding. This findings are also supported study done by Phelivanov et al. $^{28,29}$

Weight, BMI, SBP and DBP was significantly higher in phenotype $\mathrm{A}$ in comparison to phenotypes $\mathrm{B}, \mathrm{C}$ and $\mathrm{D}$ $(p<0.05)$. Waist circumference was significantly higher in phenotype $\mathrm{A}$ in comparison to phenotype $\mathrm{C}(\mathrm{p}<0.05)$.

Clinical hyperandrogenism (Ferriman-Gallwey score) was significantly higher in phenotype A in comparison to phenotypes $C$ and $D(p<0.05)$, while it was comparable with phenotype B ( $>00.05)$. Phenotype B was having significantly higher Ferriman-Gallwey score in comparison to phenotypes $\mathrm{C}$ and $\mathrm{D}(\mathrm{p}<0.05)$ and also it was higher in phenotype $\mathrm{C}$ in comparison to phenotype $\mathrm{D}$ $(\mathrm{p}<0.05)$. In addition, the overall prevalence of hirsutism features in women with PCOS whose F-G score is significantly higher than the proportion that met the "Western" description criterion of 6. Thus, racial disparity in the hirsutism parameters that need to be considered. Future studies are needed, involving more Indian women, to confirm these results.

Insulin resistance and the resulting hyperinsulinemia contribute to the reproductive abnormalities of PCOS women and various metabolic explanation is available for it. Severity of insulin resistance is varying in various phenotypes of PCOS due to relative hormonal variation. Fasting glucose was significantly higher in Phenotype A in comparison to phenotypes $\mathrm{B}, \mathrm{C}$ and $\mathrm{D} \quad(\mathrm{p}<0.05)$. Fasting insulin was significantly higher in phenotype $\mathrm{A}$ in comparison to phenotypes $\mathrm{B}, \mathrm{C}$ and $\mathrm{D}(\mathrm{p}<0.05)$.

Basal and glucose-stimulated hyperinsulinemia are well reported in PCOS women. ${ }^{30,31}$ This is secondary to profound peripheral insulin resistance. ${ }^{17,32}$ Fasting glucose levels are also higher in PCOS women secondary to increased basal hepatic glucose production, which reflects hepatic insulin resistance. ${ }^{17,33}$ Fasting glucose/insulin was significantly lower in Phenotype A in comparison to phenotypes $\mathrm{B}, \mathrm{C}$ and $\mathrm{D}(\mathrm{p}<0.05)$. The 
fasting G:I ratio represents both of these anomalies and could be expected to be a more sensitive marker for insulin resistance than either value alone, which is consistent with this study findings.

HOMA-IR with a cut-off of 2 was taken in this study. It was significantly higher in phenotype $\mathrm{A}$ in comparison to phenotypes $\mathrm{B}, \mathrm{C}$ and $\mathrm{D} \quad(\mathrm{p}<0.05)$. Highest insulin resistance is seen in phenotype A. Along with HOMA-IR, higher levels of testosterone as demonstrated in phenotypes $\mathrm{A}, \mathrm{B}$ and $\mathrm{C}$ also show higher insulin resistance. While the study done by Boston/Iceland study showed a higher insulin resistance in phenotype B alone, which is contradictory to this study findings. ${ }^{2,34}$ This difference could be due to genetic variation seen among various ethnicities, obesity and diabetes mellitus, etc.

An increased risk of metabolic syndrome in women with hyperandrogenic PCOS has been reported. ${ }^{35}$ The present study shows a trend toward higher prevalence of metabolic syndrome in all PCOS phenotypes. Insulin resistance and compensatory hyperinsulinemia appears to play a significant role in the pathophysiology of metabolic syndrome. It is therefore to be expected that the BMI and waist circumference were increased in women with phenotype A and B when compared with that of phenotype C and D.

Lipid profile was significantly more deranged in phenotype A. Total cholesterol was significantly higher in phenotype $\mathrm{A}$ in comparison to phenotypes $\mathrm{B}$ and $\mathrm{C}$ $(p<0.05)$. LDL was significantly higher in Phenotype A in comparison to phenotype $\mathrm{C}(\mathrm{p}<0.05)$. HDL was significantly lower in Phenotype $\mathrm{A}$ in comparison to phenotypes B and $C(p<0.05)$. Total triglycerides was significantly higher in phenotype $\mathrm{A}$ in comparison to phenotype $\mathrm{C}(\mathrm{p}<0.05)$. There are some authors who suggest that the clinical phenotype may arise, at least in part, from differences in the degree of metabolic dysfunction. 35

Testosterone was significantly higher in phenotype A in comparison to phenotype D $(\mathrm{p}<0.05)$, the study done by Franks et al, also reported highest level of testosterone in phenotype A and lowest in phenotype D, which corroborates with this study results. ${ }^{26}$ In this study, LH, FSH and LH:FSH ratio is significantly comparable among all the various phenotypes $(p>0.05)$. Franks et al reported that $\mathrm{LH}$ and the $\mathrm{LH} / \mathrm{FSH}$ ratio was higher in women of phenotypes $\mathrm{B}, \mathrm{C}$ and $\mathrm{A}$ when compared with that in D group, and was higher in women of phenotype $\mathrm{C}$ and $\mathrm{B}$ than those with phenotype D. ${ }^{26}$ But they also showed that variation in values of $\mathrm{FSH}, \mathrm{LH}, \mathrm{LH}-\mathrm{FSH}$ ratio, 17-hydroxyprogesterone (17-OHP), testosterone, $\mathrm{AMH}$ and vitamin D levels amongst various PCOS phenotypes were not statistically significant $(p>0.05)$.

Authors conclude that the most frequent PCOS phenotype A, is the group with all features of PCOS syndrome. The non-hyperandrogenic PCOS phenotype D, one of the new phenotypes created by the Rotterdam criteria, may represent a form of PCOS associated with a milder metabolic profile compared with the other phenotypes. Women with phenotype A and B (classic PCOS) may have the highest risk of metabolic syndrome. Subjects with PCOS defined by hyper-androgenemia are the most severely affected, with the highest androgen levels. Women with phenotype D were clearly distinguished from normal by their ovarian volume, follicle number, and irregular menstruation.

The present study carried out a comprehensive analysis of PCOS phenotypes. Authors found that phenotyping of women with PCOS related infertility may help in prognosticating the severity and fertility outcome of the disease. Although, authors had a smaller sample size, but the results showed quite comparable results with the studies done by other authors. Being limited to the Indian population, this study has not considered ethnic differences which may also play a role.

\section{CONCLUSION}

As with many other complex syndromes, PCOS does not have a common diagnostic marker to provide a gold standard for comparison. The consensus-based diagnostic criteria for PCOS in the Rotterdam criteria have defined the disease and, as such, have been useful both clinically and scientifically. Although the Rotterdam criteria were established based on expert opinions, empirical evidence has shown their advantages in predicting reproductive outcomes. As a next step, they should be tested for their capacity to direct care.

The research indicates the most prevalent PCOS phenotype is phenotypic Group A. Phenotypic category A has a higher incidence of obesity, hyperandrogenism, insulin resistance, deranged lipid profile and metabolic syndrome and are thus at a greater risk of adverse metabolic and cardiovascular effects than others. Phenotype D, on the contrary, is the least extreme or the mildest of PCOS presentations. Adiposity was associated with metabolic disorders in PCOS, and the lack of metabolic disruptions in normoandrogenic PCOS suggests decreased health risks in women with no androgen excess.

Thus, phenotypic differentiation leads to a deeper understanding of PCOS' pathophysiology and can therefore assist in predicting adverse metabolic and cardiovascular outcomes as well as poor clomiphene response. Furthermore, the detection of different phenotypes does not have diagnostic implications, but will also help to provide appropriate care and predict infertility related to PCOS among women.

\section{Funding: No funding sources}

Conflict of interest: None declared

Ethical approval: The study was approved by the Institutional Ethics Committee 


\section{REFERENCES}

1. Yildiz BO, Bozdag G, Yapici Z, Esinler I, Yarali H. Prevalence, phenotype and cardiometabolic risk of polycystic ovary syndrome under different diagnoses criteria. Hum Reprod. 2012;27(10):3067-73.

2. Adams JM, Taylor AE, Crowley WF Jr, Hall JE. Polycystic ovarian morphology with regular ovulatory cycles: insights into the patho- physiology of polycystic ovarian syndrome. J Clin Endocrimol Metab. 2004;89:4343-50.

3. Azziz R. Controversy in clinical endocrinology: diagnosis of polycystic ovarian syndrome: the Rotterdam criteria are premature. J Clin Endocrinol Metab. 2006;91(3):781-5.

4. Lujan ME, Chizen DR, Pierson RA. Diagnostic criteria for polycystic ovary syndrome: pitfalls and controversies. J Obstet Gynaecol Can. 2008;30(8):671-9.

5. Kim MJ, Lim NK, Choi YM, Kim JJ, Hwang KR, Chae SJ, et al. Prevalence of metabolic syndrome is higher among non-obese PCOS women with hyperandrogenism and menstrual irregularity in Korea. PLoS One. 2014;9(6):e99252.

6. Diamanti-Kandarakis E, Dunaif A. Insulin resistance and the polycystic ovary syndrome revisited: an update on mechanisms and implications. Endocr Rev. 2012;33(6):981-1030.

7. Gambineri A, Patton L, Altieri P, Pagotto U, Pizzi C, Manzoli L, et al. Polycystic ovary syndrome is a risk factor for type 2 diabetes: results from a long-term prospective study. Diabetes. 2012;61(9):2369-74.

8. Zawadzski JK. Diagnostic criteria for polycystic ovary syndrome: towards a rational approach. Polycystic Ovary Syndrome. 1992:39-50.

9. Rotterdam ESHRE/ASRM-Sponsored PCOS Consensus Workshop Group. Revised 2003 consensus on diagnostic criteria and long-term health risks related to polycystic ovary syndrome. Fertil Steril. 2004;81(1):19-25.

10. Azziz R, Carmina E, Dewailly D, DiamantiKandarakis E, Escobar-Morreale HF, Futterweit W. Task force on the phenotype of the polycystic ovary syndrome of the androgen E, Society $P$. The androgen excess and PCOS society criteria for the polycystic ovary syndrome: the complete task force report. Fertil Steril. 2009;91:456-88.

11. Lizneva D, Suturina L, Walker W, Brakta S, Gavrilova-Jordan L, Azziz R. Criteria, prevalence, and phenotypes of polycystic ovary syndrome. Fertil Steril. 2016;106(1):6-15.

12. Norman RJ, Hague WM, Masters SC, Wang XJ. Subjects with polycystic ovaries without hyperandrogenemia exhibit similar disturbances in insulin and lipid profiles as those with polycystic ovary syndrome. Hum Reprod. 1995;10:2258-61.

13. Dokras A, Bochner M, Hollinrake E, Markham S, Vanvoorhis B, Jagasia DH. Screening women with polycystic ovary syndrome for metabolic syndrome. Obstet Gynecol. 2005;106(1):131-7.
14. Chang RJ, Nakamura RM, Judd HL, Kaplan SA. Insulin resistance in nonobese patients with polycystic ovarian disease. J Clin Endocrinol Metab. 1983;57(2):356-9.

15. Ciaraldi TP, el-Roeiy A, Madar Z, Reichart D, Olefsky JM, Yen SS. Cellular mechanisms of insulin resistance in polycystic ovarian syndrome. J Clin Endocrinol Metab. 1992;75(2):577-83.

16. Dunaif A, Segal KR, Futterweit W, Dobrjansky A. Profound peripheral insulin resistance, independent of obesity, in polycystic ovary syndrome. Diabetes. 1989;38(9):1165-74.

17. Dunaif A, Segal KR, Shelley DR, Green G, Dobrjansky A, Licholai T. Evidence for distinctive and intrinsic defects in insulin action in polycystic ovary syndrome. Diabetes. 1992;41(10):1257-66.

18. Fritz MA, Sreroff L. Chronic anovulation and the polycystic ovary syndrome. In: Baltimore MD, ed. Clinical Gynecologic Endocrinology and Infertility. 8th Ed. Philadelphia: Lippincott Williams and Wilkins; 2011:495-532.

19. Hettihewa LM, Shalika P, Jayasinghe SS, Gunasekara SW, Weerarathna TP. Comparison of insulin resistance by indirect methods-HOMA, QUICKI and McAuley-with fasting insulin in patients with type 2 diabetes in Galle, Sri Lanka: A pilot study. Online J Health Allied Sci. 2006;1:2.

20. Katz A, Nambi SS, Mather K, Baron AD, Follmann DA, Sullivan G, et al. Quantitative insulin sensitivity check index: a simple, accurate method for assessing insulin sensitivity in humans. J Clin Endocrinol Metab. 2000;85(7):2402-10.

21. Matthews DR, Hosker JP, Rudenski AS, Naylor BA, Treacher DF, Turner RC. Homeostasis model assessment: insulin resistance and beta-cell function from fasting plasma glucose and insulin concentrations in man. Diabetologia. 1985;28(7):412-9.

22. McAuley KA, Williams SM, Mann JI, Walker RJ, Lewis-Barned NJ, Temple LA, et al. Diagnosing insulin resistance in the general population. Diabetes Care. 2001;24(3):460-4.

23. Nishida C, Ko GT, Kumanyika S. Body fat distribution and noncommunicable diseases in populations: overview of the 2008 WHO expert consultation on waist circumference and waist-hip ratio. Eur J Clin Nutr. 2010;64(1):2-5.

24. Wild RA, Vesely S, Beebe L, Whitsett T, Owen W. Ferriman Gallwey self-scoring I: performance assessment in women with polycystic ovary syndrome. J Clin Endocrinol Metab. 2005;90(7):4112-4.

25. Whitaker L, Critchley HO. Abnormal uterine bleeding. Best Pract Res Clin Obstet Gynaecol. 2016;34:54-65

26. Franks S, McCarthy MI, Hardy K. Development of polycystic ovary syndrome: involvement of genetic and environmental factors. Int $\mathbf{J}$ Androl. 2006;29(1):278-85. 
27. Urbanek M. The genetics of the polycystic ovary syndrome. Nat Clin Pract Endocrinol Metab. 2007;3(2):103-11.

28. Głuszak O, Stopińska-Głuszak U, Glinicki P, Kapuscinska R, Snochowska H, Zgliczynski W, et al. Phenotype and metabolic disorders in polycystic ovary syndrome. ISRN Endocrinol. 2012;2012:569862.

29. Pehlivanov B, Orbetzova M. Characteristics of different phenotypes of polycystic ovary syndrome in a Bulgarian population. Gynecol Endocrinol. 2007;23(10):604-9.

30. Burghen GA, Givens JR, Kitabchi AE. Correlation of hyperandrogenism with hyperinsulinism in polycystic ovarian disease. J Clin Endocrinol Metab. 1980;50(1):113-6.

31. Dunaif A, Graf M, Mandeli J, Laumas V, Dobrjansky A. Characterization of groups of hyperandrogenic women with acanthosis nigricans, impaired glucose tolerance, and/or hyperinsulinemia. J Clin Endocrinol Metab. 1987;65(3):499-507.

32. Dunaif A, Finegood DT. Beta-cell dysfunction independent of obesity and glucose intolerance in the polycystic ovary syndrome. J Clin Endocrinol Metab. 1996;81(3):942-7.

33. Dunaif A. Insulin resistance and the polycystic ovary syndrome: mechanism and implications for pathogenesis. Endocr Rev. 1997;18(6):774-800.

34. Polson DW, Adams J, Wadsworth J, Franks S. Polycystic ovaries-a common finding in normal women. Lancet. 1988;1(8590):870-2.

35. Chang WY, Knochenhauer ES, Bartolucci AA, Azziz R. Phenotypic spectrum of polycystic ovary syndrome: clinical and biochemical characterization of the three major clinical subgroups. Fertil Steril. 2005;83(6):1717-23.

Cite this article as: Gupta D, Upadhyaya R, Bhati A. Study of prevalence of insulin resistance and other metabolic abnormalities in various phenotypes of polycystic ovary syndrome in central India. Int J Reprod Contracept Obstet Gynecol 2020;9:2978-86. 